\title{
Treatment of severely open tibial fractures, non-unions, and fracture-related infections with a gentamicin-coated tibial nail-clinical outcomes including quality of life analysis and psychological ICD-10- based symptom rating
}

\author{
Nike Walter ${ }^{1,2}$, Daniel Popp ${ }^{1}$, Viola Freigang ${ }^{1}$, Michael Nerlich¹, Volker Alt ${ }^{1}$ and Markus Rupp ${ }^{1 *}$
}

\begin{abstract}
Background: Implant-associated infections depict a major challenge in orthopedics and trauma surgery putting a high burden on the patients and health care systems, strongly requiring improvement of infection prevention and of clinical outcomes. One strategy includes the usage of antimicrobial-coated implants. We evaluated outcomes after surgical treatment using a gentamicin-coated nail on (i) treatment success in terms of bone consolidation, (ii) absence of infection, and (iii) patient-reported quality of life in a patient cohort with high risk of infection/ reinfection and treatment failure.

Methods: Thirteen patients with open tibia fractures $(n=4)$, non-unions $(n=2)$, and fracture-related infection $(n=7)$ treated with a gentamicin-coated intramedullary nail (ETN Protect ${ }^{\mathrm{TM}}$ ) were retrospectively reviewed. Quality of life was evaluated with the EQ-5D, SF-36, and with an ICD-10-based symptom rating (ISR).

Results: At a mean follow-up of 2.8 years, 11 of the 13 patients (84.6\%) achieved bone consolidation without any additional surgical intervention, whereas two patients required a revision surgery due to infection and removal of the implant. No specific implant-related side effects were noted. Quality of life scores were significantly lower compared to a German age-matched reference population. The mean ISR scores revealed mild psychological symptom burden on the scale depression.
\end{abstract}

Conclusion: The use of a gentamicin-coated intramedullary nail seems to be reasonable in open fractures and revision surgery for aseptic non-union or established fracture-related infection to avoid infection complications and to achieve bony union. Despite successful treatment of challenging cases with the gentamicin-treated implant, significantly reduced quality of life after treatment underlines the need of further efforts to improve surgical treatment strategies and psychological support.

Keywords: Antimicrobial-coated nails, Infection prevention, Quality of life

\footnotetext{
*Correspondence: markus.rupp@ukr.de

'Department for Trauma Surgery, University Medical Center Regensburg, Franz-Josef-Strauß-Allee 11, 93053 Regensburg, Germany

Full list of author information is available at the end of the article
}

C C The Author(s). 2021 Open Access This article is licensed under a Creative Commons Attribution 4.0 International License, which permits use, sharing, adaptation, distribution and reproduction in any medium or format, as long as you give appropriate credit to the original author(s) and the source, provide a link to the Creative Commons licence, and indicate if changes were made. The images or other third party material in this article are included in the article's Creative Commons licence, unless indicated otherwise in a credit line to the material. If material is not included in the article's Creative Commons licence and your intended use is not permitted by statutory regulation or exceeds the permitted use, you will need to obtain permission directly from the copyright holder. To view a copy of this licence, visit http://creativecommons.org/licenses/by/4.0/ The Creative Commons Public Domain Dedication waiver (http://creativecommons.org/publicdomain/zero/1.0/) applies to the data made available in this article, unless otherwise stated in a credit line to the data. 


\section{Introduction}

Fracture healing can be a complex and tedious process. Diverse treatment strategies utilize fracture fixation devices to restore bone consolidation and enhance patients' quality of life. However, implant-associated infections depict a major challenge in orthopedics and trauma surgery putting a high burden on the patients and health care systems [1]. The risk of developing a posttraumatic infection is multifactorial with reported rates of $1-2 \%$ for closed fractures ranging up to exceeding 30\% for Gustilo-Anderson type III open tibia fractures [2-4]. The prevalence is expected to increase, as the incidence of long bone fractures is projected to rise, especially in the elderly [5]. Depending on injury severity, success rates only vary between $70-90 \%$ with a recurrence of the disease in $6-9 \%$ of the patients [6-8]. Consequences are often fatal. Several limitations such as immobility up to amputations of the affected limb, prolonged length of stay in hospital, multiple surgeries, side effects of antibiotic medication, and further socioeconomic issues are often not to be avoided despite a variety of prevention concepts [9]. Hence, the improvement of infection prevention in fracture care is strongly required [1]. With the ground-breaking discovery of the release of antibiotics from poly(methyl methacrylate) (PMMA) bone cement in 1970, the door to prevent colonization of implants and thusly biofilm formation was opened [10]. Nowadays different antimicrobial-coated implants are available [11]. However, their long-term durability is not guaranteed and high level of evidence studies which underpin their benefit are still lacking [12]. For use in trauma surgery, a gentamicin poly(D, L-lactide) (PDLLA) matrix coating for tibial nails has been developed and is available on the European market since August 2005 [1].

Clinical studies reporting on outcomes after gentamicincoated nail treatment are rare with heterogeneous designs. Hence, we aimed at evaluating the outcome of surgical treatment with gentamicin-coated nails on (i) treatment success defined as bone consolidation as well as absence of recurrence of infection, and (ii) patient-reported quality of life in a patient cohort with the indications Gustilo-Anderson type III open tibia fractures, non-unions or fracture-related infections, as these depict challenging high risk of reinfection and treatment failure cases.

\section{Material and methods}

Patients treated with a gentamicin-coated intramedullary nail (ETN PROtect ${ }^{\mathrm{TM}}$ ) in our department between September 2012 and January 2020 were prospectively included. Informed consent was obtained from all individual participants included in the study. The study was approved by the institutional ethics committee of the University Clinic of Regensburg according to the Helsinki Convention (file number 20-1680-101). Patients' characteristics were retrospectively retrieved from the hospitals electronic patient files system. Treatment indications included open tibia fractures, non-unions, and fracture-related infections (FRI). Open fractures were classified according to the Gustilo-Anderson classification [13]. Non-unions were considered as cessation of bone healing within 6 months after trauma and the expectation that no consolidation will be achieved without accurate treatment [14]. Infections were defined by the criteria of the FRI consensus definition [15]. Clinical records and radiographs were reviewed with a minimum follow-up time of 6 months after implantation of the gentamicin-coated nail. Achieved bone consolidation was determined with an evaluated RUST score $>10$ [16]. Treatment failure was defined as required revision surgery due to FRI or non-union. Recurrence of infection with necessary revision surgery was assessed beginning with implantation of the intramedullary nails.

Patient-related outcome and quality of life was assessed using the German Short-Form 36 (SF-36) and EQ-5D scores as well as an ICD-10-based symptom rating (ISR) [17, 18]. The latter is an inventory frequently used in psychosomatic anamnesis. It consists of 29 items and covers various mental syndromes with subscales for depression, anxiety, obsessive/compulsive disorders, somatoform disorders, and eating disorders [19]. The EQ-5D is a well-established generic quality of life instrument developed by the EuroQol group comprising five questions concerning the functional domains mobility, self-care, everyday life activities, pain/discomfort, and anxiety/depression [20]. The items were converted into a single EQ index value using German norm data weights [21]. Additionally, the EQ-5D was evaluated using the visual analog scale (VAS) method [22]. The widely used SF-36 health survey captures the general health status with 36 questions in eight functional domains: physical function, role physical, bodily pain, general health, vitality, social function, role emotional, and mental health. Summary scores for the physical and mental component were calculated using normative data from a German national health interview and examination survey conducted in 1998 with 7124 participants [23]. Quality of life scores were compared to normative data [23, 24].

Data was analyzed using SPSS statistics version 24.0 (IBM, SPSS Inc., Armonk, NY). Descriptive statistics were calculated for all variables. Continuous variables were expressed as the mean and standard deviation. For comparisons between continuous variables independent $\mathrm{t}$-tests were performed after determining the distribution was appropriate for parametric testing by Levene's test. Significance was set at $p<.001$.

\section{Results}

Thirteen patients ( 5 women; 8 men; mean age $43.9 \pm$ 15.8 years) were included in the analysis (Table 1 ). The mean follow-up time was 2.8 years with a minimum 
follow-up time of 6 months after implantation of the gentamicin-coated nail. Four patients (30.77\%) had a polytrauma.

The indication for the treatment with an ETN PROtect $^{\mathrm{TM}}$ a fracture-related infection in seven cases (53.85\%), aseptic non-union in two cases (15.39\%), and open fractures in four cases (30.76\%). Initial fractures were classified as Gustilo-Anderson type II in one case (7.69\%), as type IIIa in three cases (23.08\%), as type IIIb in four cases (30.77\%), and as type IIIc in two cases (15.39\%). Three patients (23.08\%) had closed fractures with primary application of an external fixator before intramedullary nailing was performed. Eleven patients achieved bone consolidation within the time of the follow-up (84.62\%), whereas an infection occurred after treatment with an ETN PROtect ${ }^{\mathrm{TM}}$ in two cases (15.39\%). Subsequently, these were treated with removal of the gentamicin-coated nail after 3.4 months and 5.1 months, respectively.

Quality of life was evaluated for the eleven successfully treated patients ( 4 women; 7 men; mean age $40.8 \pm 15.3$ years) at a mean follow-up time of 3.2 years (range $0.8-$ 7.7 years). The resulting mean physical health component score (PCS) of the SF-36 was $40.18 \pm 13.1$, and the mean mental health component score (MCS) of the SF-36 was $39.58 \pm 13.6$. In comparison with normative data from Germany, our patients score lower in the physical health component $\left(\mathrm{PCS}_{\mathrm{Norm}}=48.4 \pm 9.2, p=.009\right)$ as well as in the mental health component of the SF-36 $\left(\mathrm{MCS}_{\mathrm{Norm}}=\right.$ $50.9 \pm 8.8, p<.001$ ), which depicts $83.1 \%$ and $77.8 \%$ of the summary scores obtained from the reference population, respectively (Fig. 1). The SF-36 subdomain analysis resulted in mean values of $53.6 \pm 16.7$ for physical function, $47.7 \pm 16.4$ for physical role, $55.5 \pm 18.0$ for bodily pain, $59.5 \pm 21.3$ for general health, $43.6 \pm 17.2$ for vitality, 64.7 \pm 19.4 for social functioning, $51.5 \pm 17.8$ for emotional role, and $60.0 \pm 18.8$ for mental health. Hence, our cohort reached $62.8 \%$ for physical function $(85.4 \pm 20.7, p<$ $.001), 58.0 \%$ for physical role $(82.3 \pm 32.7, p=.002), 82.3 \%$ for bodily pain $(67.4 \pm 25.9, p=.123), 89.5 \%$ for general health $(66.4 \pm 18.2, p=.192), 72.7 \%$ for vitality $(60.0 \pm$ $17.8, p=.006), 76.0 \%$ for social functioning $(86.4 \pm 19.9, p$ $=.002), 57.8 \%$ for emotional role $(89.1 \pm 26.7, p<.001)$, and $82.8 \%$ for mental health $(72.5 \pm 16.7, p=.020)$ of the normative values (Fig. 2).

The mean EQ-5D VAS rating reached $62.6 \pm 24.5$, which depicts $75.9 \%$ of the score of $82.5 \pm 0.6$ obtained from an age-matched reference population $(p<.001)$. The mean EQ-5D index value was $0.769 \pm 0.25$, reaching $79.9 \%$ of the age-matched normative value $0.966(p<$ .001) calculated based on a country-specific TTO value set [24]. In the subdimensions of the EQ-5D, patients showed limited results especially in mobility and pain/ discomfort (Fig. 3). In total, $54.6 \%$ of the patients reported problems with mobility (compared to $15.9 \%$ of the German reference), $18.2 \%$ with self-care (compared to a norm value of $2.7 \%$ ), $45.5 \%$ with usual activities (versus 9.9\%), 90.9\% with pain/discomfort (compared to $27.6 \%$ ), and $45.5 \%$ with anxiety/depression ( $4.3 \%$ of the normative population).

The mean total score of the ISR was $0.64 \pm 0.26$. The mean ISR subdimension scores reached $1.23 \pm 0.28$ for depression, $0.66 \pm 0.30$ for anxiety, $0.30 \pm 0.23$ for obsessive/compulsive disorders, $0.39 \pm 0.21$ for somatoform disorders, and $0.58 \pm 0.14$ for eating disorders, respectively (Fig. 4). Total scores above 0.6 , scores above 1.0 for depression, anxiety, and obsessive/compulsive disorders, scores above 0.75 for somatoform disorders and scores above 0.67 for eating disorders are interpreted as mild psychological symptom burden [19].

Table 1 Patient characteristics

\begin{tabular}{llllllll}
\hline & $\begin{array}{l}\text { Age } \\
\text { (years) }\end{array}$ & Gender & Fracture type (Gustilo-Anderson) & Indication & Bone consolidation & Polytrauma & Treatment failure \\
\hline 1 & 22 & Female & 3a, open & Aseptic non-union & Yes & Yes & No \\
2 & 53 & Male & 3c, open & Fracture & Yes & No & No \\
3 & 41 & Female & 3 c, open & Fracture & Yes & Yes & No \\
4 & 51 & Male & 3a, open & FRl & Yes & No & No \\
5 & 61 & Male & 2, open & Aseptic non-union & Yes & Yes & No \\
6 & 64 & Male & 3a, open & FRl & Yes & Yes & No \\
7 & 27 & Male & 3b, open & Fracture & Yes & No & No \\
8 & 31 & Male & closed & FRl & Yes & No & No \\
9 & 19 & Female & closed & FRl & Yes & No & No \\
10 & 32 & Female & 3b, open & FRl & Yes & No & Yes \\
11 & 41 & Male & 3b, open & Fracture & FRl & No & No \\
12 & 51 & Male & 3b, open & FRl & No & Yes \\
\hline
\end{tabular}




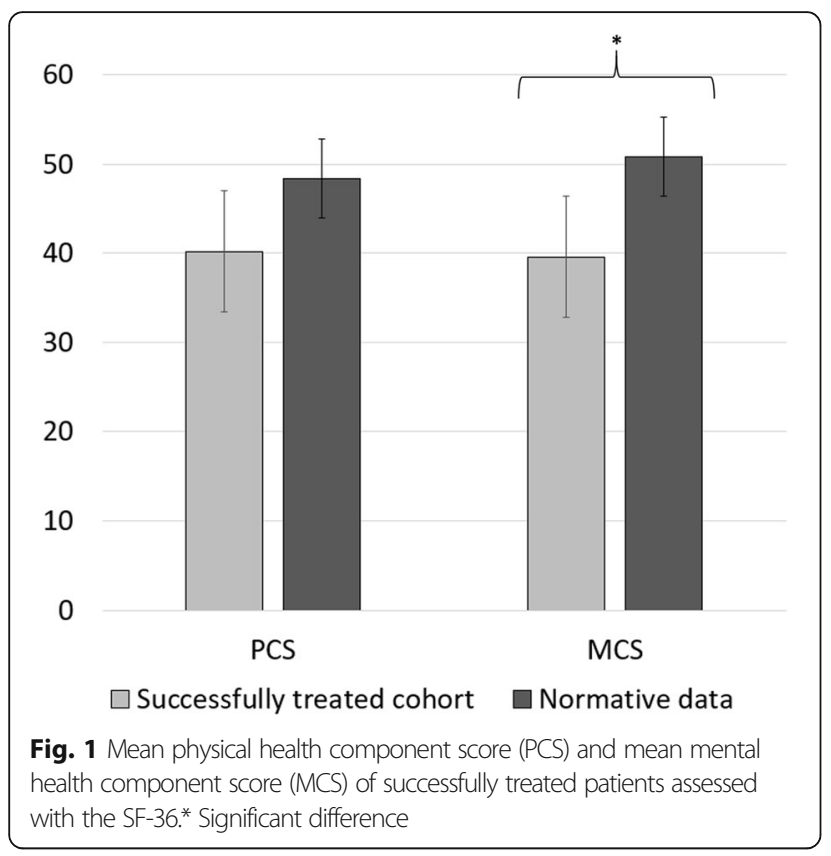

The two cases considered as treatment failure (1 woman, 1 man; mean age 61.4 \pm 13.7 years) reported a mean PCS of the SF-36 of $24.88 \pm 4.12$ and a mean MCS of $34.07 \pm 4.6$. The SF-36 subdomain analysis resulted in mean values of $12.5 \pm 2.1$ for physical function, zero for physical role, $37.0 \pm 13.8$ for bodily pain, $45.0 \pm$ 4.5 for general health, $32.5 \pm 2.2$ for vitality, $56.3 \pm 30.6$ for social functioning, zero for emotional role, and 58.0 \pm 10.5 for mental health. Lower scores in comparison to the successfully treated subgroup were also reflected in the mean EQ-5D index value of $0.633 \pm 0.22$ with a mean VAS rating of $45.0 \pm 7.07$. The mean total score of the ISR was $0.86 \pm 0.43$. The mean ISR subdimension scores reached $1.0 \pm 0.82$ for depression, $1.1 \pm 0.48$ for anxiety, $0.83 \pm 0.29$ for obsessive/compulsive disorders anxiety, $1.0 \pm 0.0$ for somatoform disorders, and $0.50 \pm$ 0.50 for eating disorders.

\section{Discussion}

In this study, the outcome of the use of a gentamicincoated intramedullary tibia nail, ETN PROtect ${ }^{\mathrm{TM}}$ was evaluated in a cohort of high risk of reinfection and treatment failure. Treatment success in terms of achieved bone consolidation and no required revision surgery due to infection was observed in eleven of thirteen patients.

Studies accessing the clinical outcome and especially patients' quality of life after the use of gentamicincoated nails in tibia fractures and revision cases are rare. Fuchs and colleagues evaluated 21 patients treated with a UTN PROtect Tibial Nail (DePuy Synthes, Bettlach, Switzerland) in a prospective case series with closed and open tibia fractures, as well as revisions, reporting no infection and radiographic union in 11 of 19 patients at a follow-up of 6 months [25]. Metsemakers et al. included nine patients with a Gustilo-Anderson grade II or grade III open tibial fracture, four infected non-unions, two acute tibial shaft fractures pretreated with external fixation, and one aseptic non-union with a soft-tissue defect in a retrospective analysis. The authors report no

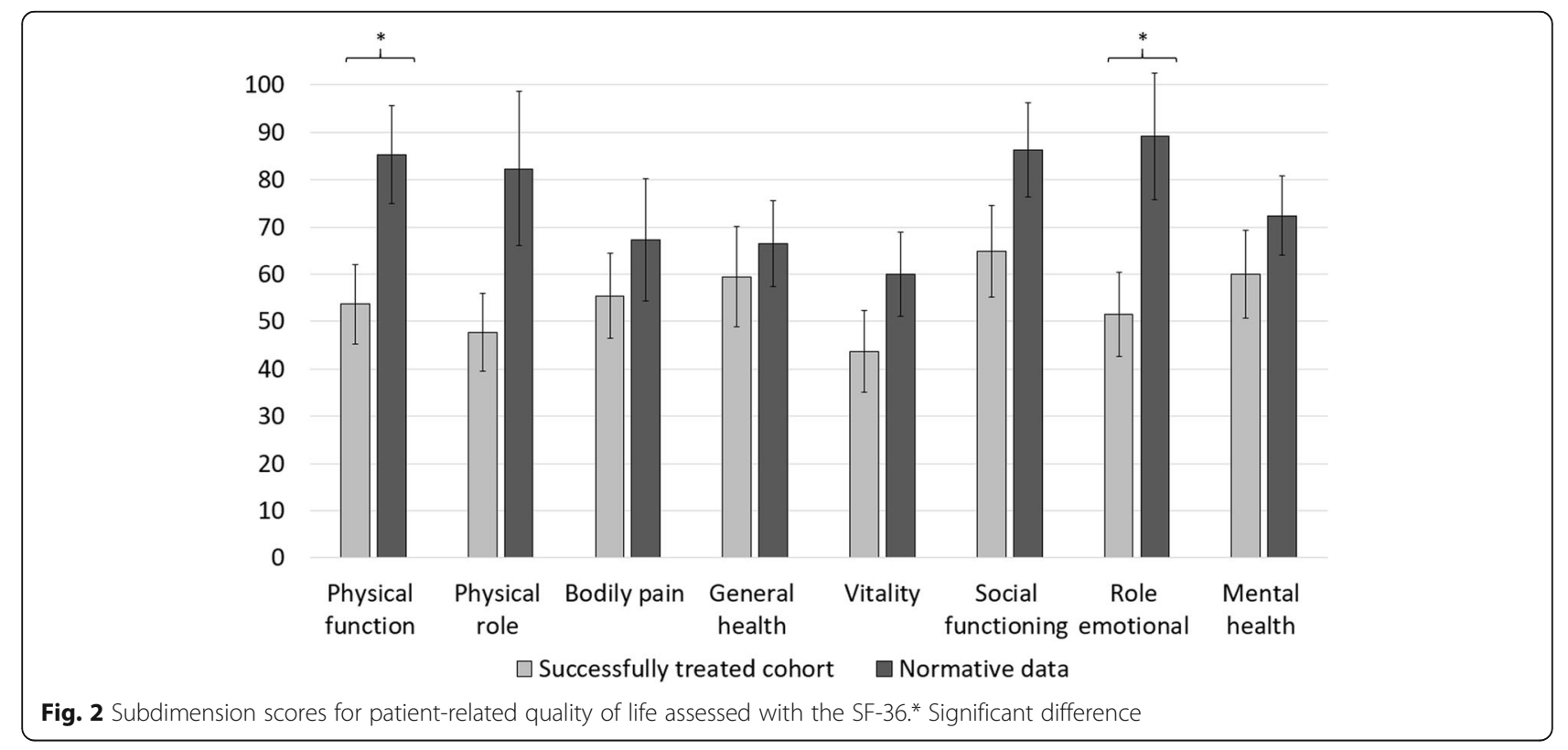




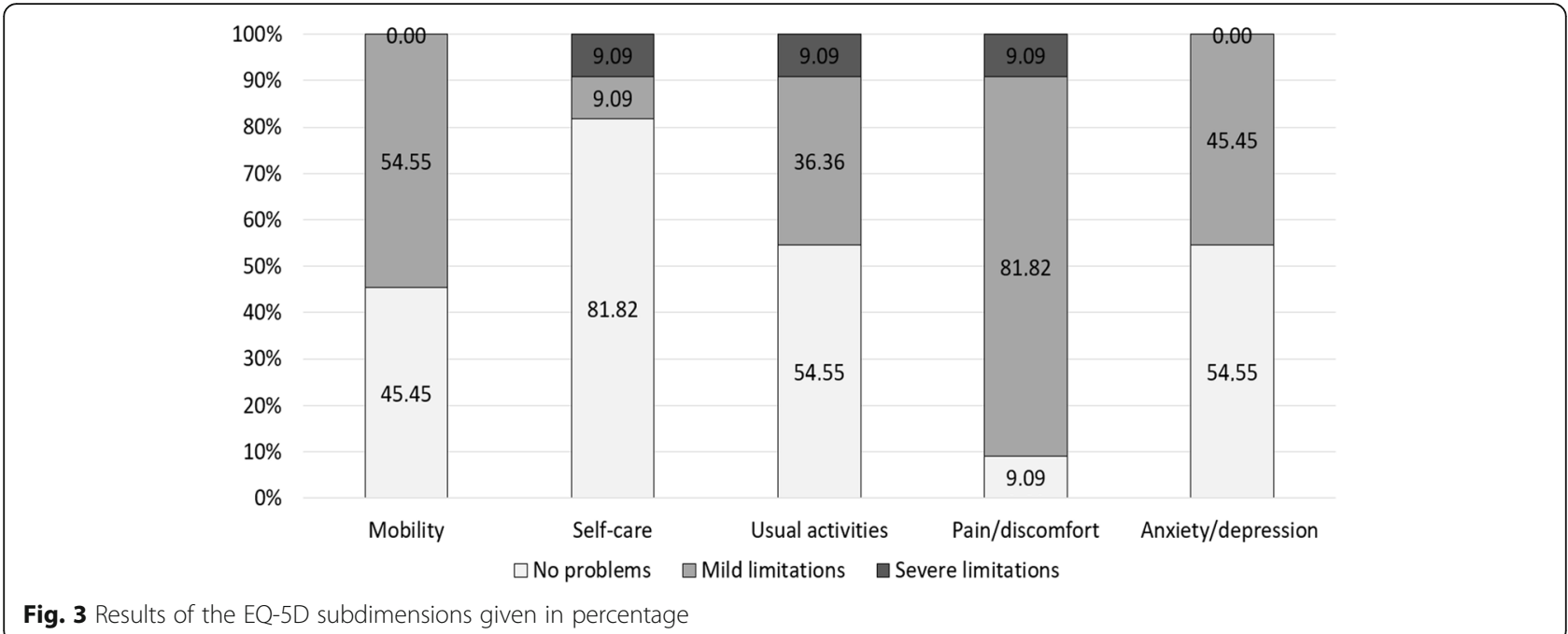

infection at a follow-up of 18 months [26]. Another analysis of 99 patients with open or closed tibial fractures as well as non-union revision cases treated with a gentamicin-coated titanium nail, resulted in observed infection in 4 of 55 patients after fracture and in 2 of 26 patients after revision surgery at a 18 months follow-up [27]. Vicenti and colleagues included 17 patients, who all achieved bone consolidation at a mean time of 7.18 months concluding that gentamicin-coated nails in association with the RIA system depict a safe and effective treatment of non-unions. They further showed a significant improvement of the quality of life, evaluated with the EQ-5D and the mean VAS for pain at a 3 months follow-up [28]. Additionally, better bone healing was reported at a 6 months follow-up in a cohort of 14 patients treated with gentamicin-coated nails compared to 14 cases treated with regular nailing and no gentamicin release into the systemic circulation above the lowest detectable level of $0.2 \mathrm{mg} / \mathrm{dL}$ could be determined in serum samples of patients treated with the ETN PROtect $^{\mathrm{TM}}[29,30]$. Hence, the application of a gentamicincoated intramedullary nail (ETN Protect ${ }^{\mathrm{TM}}$ ) seems reasonable to prevent implant-associated infections.

The patient-reported outcome measures reflect the high physical and mental burden resulting from the complex injuries even after successful bony consolidation and

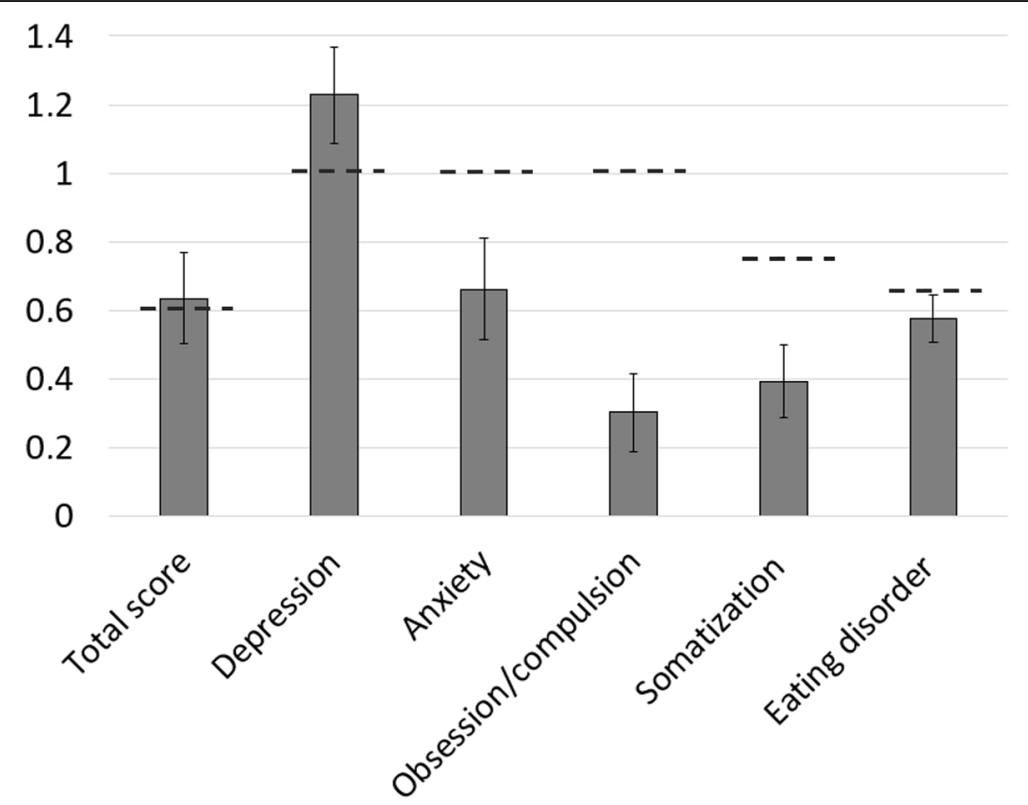

Fig. 4 Mean values of the ISR scores obtained from successfully treated patients. The dotted line illustrates the border to considered mild psychological symptom burden 
avoidance of infections/recurrence of infections. Quality of life of patients, which were successfully treated, was significantly lower compared to a German aged-matched reference population regarding the EQ-5D index value, the EQ-5D VAS rating, mental health component of the SF36 , as well as the SF-36 subdimensions physical function, physical role, and role emotional. The ISR showed mild psychological symptom burden in particular regarding depression. The two treatment failure cases showed reduced quality of life in comparison to successfully treated patients in the summary scores, as well as the subdimensions of the SF-36, the EQ-5D index value as well as the EQ-5D VAS rating and the mean total ISR score.

These finding are in line with other studies providing first insights into the serious consequences following fractures, non-unions, and fracture-related infections on patients' physical and mental wellbeing [31-33]. For instance, Brinker et al. assessed the quality of life in 237 patients with tibial shaft fracture non-unions $(14.8 \%$ infected) and report a mean SF-12 mental health component score of $42.3 \pm 7.1$ and a mean SF-12 physical health component score of $27.4 \pm 6.7$. Comparing their findings to different medical conditions, they show that the impact of a non-union situation regarding the physical, as well as mental health component is worse than congestive heart failure, type- 2 diabetes mellitus, and myocardial infarction among others [32]. Recently, a meta-analysis was calculated for a direct comparison between the non-union and union situation showing a mean difference of - 11.94 scores for the SF-12 physical health component and a difference of -6.42 for the SF12 mental health component [31]. These results are in accordance with our findings, showing a difference of 15.3 for the PCS and - 4.9 for the MCS assessed with the SF-36 between successfully treated patients who achieved bone consolidation and cases considered as treatment failure. Further, the impact of required revision surgeries has been highlighted by a study comparing outcomes after femoral shaft fractures treated with plate fixation and intramedullary nailing. Here, patients who did not require a reoperation achieved an EQ-5D index value of 0.95 after 1 year in comparison to a value of 0.83 for revision cases [34]. Additionally, the reported EQ-5D index value of $0.769 \pm 0.25$ is comparable to patients with multiple trauma, for which an value of $0.76 \pm$ 0.27 has been calculated 24 months postoperatively [35] as well as to patients requiring trauma related surgery, who achieved an index value of $0.73 \pm 0.29$ with a follow-up time of 12 months [35, 36]. Also, the EQ-5D VAS score was similar to values reported from patients with pelvic ring fractures after a mean follow-up of 4.2 years [37]. Therefore, the reduced quality of life might be rather attributable to the severity of injuries than to the use of the ETN nail for the treatment. In general, patient-related outcome measures and the explicit investigation of the psychological impact of injuries should be deemed as a future direction of research as an underestimation of the burden of injury may affect resource allocation, necessary prevention priorities and may hinder the implementation of counseling as part of the standard care in trauma surgery. Newly emerging treatment strategies and prevention methods as well as interdisciplinary approaches should be implemented to restore and improve the overall quality of life of patients with complicated fractures, non-unions, and fracture-related infections.

Limitations of our study are the usual suspects. The study is a retrospective case series including patients with different indications for intramedullary nailing with a gentamicin-coated intramedullary nail (ETN PROtect ${ }^{\mathrm{TM}}$ ). Due to the small sample size, subgroup analysis was not deemed applicable as results may be statistically underpowered. Whereas the case number is comparatively low, the period in which patients have been treated with the ETN nail is long. Reasons for less numbers are the use of gentamicin-coated intramedullary nails only in patients with high risk of bone infection and longterm follow-up for clinical and radiological outcome. Treatment standards in fracture care did not change during this time frame. Thus, we believe the long study period rather enables a sound follow-up period than limit the value of the reported data.

\section{Conclusion}

In conclusion, the application of a gentamicin-coated intramedullary nail (ETN PROtect ${ }^{\mathrm{TM}}$ ) seems to be reasonable to avoid implant related bone infection in complex fractures and revision cases, when respecting current treatment standards in fracture care and infection surgery. Low quality of life after treatment underlines the need of further efforts to improve surgical treatment strategies and psychological support in complicated and challenging cases.

\section{Abbreviations \\ FRI: Fracture-related infection; ISR: ICD-10-based symptom rating; PMMA: Poly(methyl methacrylate); PDLLA: Poly(D, L-lactide)}

\section{Authors' contributions \\ NW, MN, VA, and MR conceptualized the study. NW and MR analyzed the results. All authors interpreted the results. NW, DP, and VF visualized the results. NW wrote the first draft of the manuscript. All authors edited the manuscript, read and approved the final version.}

Funding

Open Access funding enabled and organized by Projekt DEAL.

Availability of data and materials

The datasets analyzed during the current study are available from the corresponding author on reasonable request. 


\section{Declarations}

\section{Competing interest}

The authors declare that they have no competing interests.

\section{Ethics approval and consent to participate}

The study was approved by the institutional ethics committee of the University Clinic of Regensburg (file number 20-1680-101) and was performed in accordance with the ethical standards in the 1964 Declaration of Helsinki. Informed consent was obtained from all individual participants included in the study.

\section{Author details}

'Department for Trauma Surgery, University Medical Center Regensburg, Franz-Josef-Strauß-Allee 11, 93053 Regensburg, Germany. ${ }^{2}$ Department for Psychosomatic Medicine, University Medical Center Regensburg, Regensburg, Germany.

Received: 6 January 2021 Accepted: 6 April 2021

Published online: 17 April 2021

\section{References}

1. Alt V. Antimicrobial coated implants in trauma and orthopaedics - a clinical review and risk-benefit analysis. Injury. 2017;48(3):599-607. https://doi.org/1 0.1016/j.injury.2016.12.011.

2. Trampuz A, Zimmerli W. Diagnosis and treatment of infections associated with fracture-fixation devices. Injury. 2006;37(Suppl 2):S59-66. https://doi. org/10.1016/j.injury.2006.04.010

3. Ktistakis I, Giannoudi M, Giannoudis PV. Infection rates after open tibial fractures: are they decreasing? Injury. 2014;45(7):1025-7. https://doi.org/10.1 016/j.injury.2014.03.022.

4. Metsemakers WJ, Onsea J, Neutjens E, Steffens E, Schuermans A, McNally M, et al. Prevention of fracture-related infection: a multidisciplinary care package. Int Orthop. 2017;41(12):2457-69. https://doi.org/10.1007/s00264-01 7-3607-y.

5. Court-Brown CM, Duckworth AD, Clement ND, McQueen MM. Fractures in older adults. A view of the future? Injury. 2018;49(12):2161-6. https://doi. org/10.1016/j.injury.2018.11.009.

6. Bose D, Kugan R, Stubbs D, McNally M. Management of infected nonunion of the long bones by a multidisciplinary team. Bone Joint J. 2015;97-B(6): 814-7. https://doi.org/10.1302/0301-620X.97B6.33276.

7. Metsemakers WJ, Kuehl R, Moriarty TF, Richards RG, Verhofstad MHJ, Borens O, et al. Infection after fracture fixation: Current surgical and microbiological concepts. Injury. 2018;49(3):511-22. https://doi.org/10.1016/j.injury.2016.09.019.

8. Bezstarosti H, Van Lieshout EMM, Voskamp LW, et al. Insights into treatment and outcome of fracture-related infection: a systematic literature review. Arch Orthop Trauma Surg. 2019;139(1):61-72. https://doi.org/10.1007/s004 02-018-3048-0.

9. Rupp M, Popp D, Alt V. Prevention of infection in open fractures: Where are the pendulums now? Injury. 2020;51(Suppl 2):S57-63. https://doi.org/10.101 6/j.injury.2019.10.074.

10. Buchholz HW, Engelbrecht $\mathrm{H}$. [Depot effects of various antibiotics mixed with Palacos resins]. Chirurg. 1970;41:511-515

11. Greco T, Vitiello R, Cazzato $G$, et al. Intramedullary antibiotic coated nail in tibial fracture: a systematic review. J Biol Regul Homeost Agents. 2020;34(3 Suppl. 2):63-9.

12. Romanò $\mathrm{CL}$, Tsuchiya $\mathrm{H}$, Morelli I, Battaglia AG, Drago L. Antibacterial coating of implants: are we missing something? Bone Joint Res. 2019;8(5): 199-206. https://doi.org/10.1302/2046-3758.85.BJR-2018-0316.

13. Gustilo RB, Anderson JT. Prevention of infection in the treatment of one thousand and twenty-five open fractures of long bones: retrospective and prospective analyses. J Bone Joint Surg Am. 1976;58(4):453-8. https://doi. org/10.2106/00004623-197658040-00004.

14. Frölke JP, Patka P. Definition and classification of fracture non-unions. Injury. 2007:(Suppl 2):S19-22.

15. Metsemakers W, Morgenstern M, McNally $M$, et al. Fracture-related infection: a consensus on definition from an international expert group. Injury. 2018; 49(3):505-10. https://doi.org/10.1016/j.injury.2017.08.040.

16. Cooke ME, Hussein Al, Lybrand KE, Wulff A, Simmons E, Choi JH, et al. Correlation between RUST assessments of fracture healing to structural and biomechanical properties. J Orthop Res. 2018;36(3):945-53. https://doi.org/1 0.1002/jor.23710.

17. Bullinger M, Kirchberger I, Ware J. The German SF-36 health survey translation and psychometric testing of a generic instrument for the assessment of health-related quality of life. J Public Health. 1995;3(1):21-36. https://doi.org/10.1007/BF02959944.

18. Brooks R. EuroQol: the current state of play. Health Policy. 1996;37(1):53-72. https://doi.org/10.1016/0168-8510(96)00822-6.

19. Tritt K, Von Heymann F, Zaudig M, et al. Development of the "ICD-10Symptom-Rating"(ISR) questionnaire. Z Psychosom Med Psychother. 2018; 54(4):409-18.

20. Devlin NJ, Brooks R. EQ-5D and the EuroQol group: past, present and future Appl Health Econ Health Policy. 2017;15(2):127-37. https://doi.org/10.1007/ s40258-017-0310-5.

21. Claes C, Greiner W, Uber A, von der Schulenburg JM G. An interview-based comparison of the TTO and VAS values given to EuroQol states of health by the general German population. In: Greiner W, Graf vd, Schulenburg J-M, Piercy J, editors. EuroQol Plenary Meeting, 1-2 October 1998. Discussion papers. Centre for Health Economics and Health Systems Research, University of Hannover, Germany: Uni-Verlag Witte; 1999. p. 13-39.

22. EuroQol Group. EuroQol--a new facility for the measurement of healthrelated quality of life. Health Policy. 1990;16(3):199-208.

23. Ellert U, Kurth BM. Methodological views on the SF-36 summary scores based on the adult German population. Bundesgesundheitsbl Gesundheitsforsch Gesundheitsschutz. 2004;47(11):1027-32. https://doi.org/1 0.1007/s00103-004-0933-1.

24. Szende A, Janssen B, Cabases J. Self-reported population health: an international perspective based on EQ-5D. Dordrecht Springer Netherlands. 2014:20-2.

25. Fuchs $T$, Stange $R$, Schmidmaier G, Raschke MJ. The use of gentamicincoated nails in the tibia: preliminary results of a prospective study. Arch Orthop Trauma Surg. 2011;131(10):1419-25. https://doi.org/10.1007/s00402011-1321-6.

26. Metsemakers WJ, Reul M, Nijs S. The use of gentamicin-coated nails in complex open tibia fracture and revision cases: A retrospective analysis of a single centre case series and review of the literature. Injury. 2015:46(12): 2433-7. https://doi.org/10.1016/j.injury.2015.09.028.

27. Schmidmaier G, Kerstan M, Schwabe P, Südkamp N, Raschke M. Clinical experiences in the use of a gentamicin-coated titanium nail in tibia fractures. Injury. 2017:48(10):2235-41. https://doi.org/10.1016/j.injury.2017.07.008.

28. Vicenti G, Bizzoca D, Cotugno D, Carrozzo M, Riefoli F, Rifino F, et al. The use of a gentamicin-coated titanium nail, combined with RIA system, in the management of non-unions of open tibial fractures: A single centre prospective study. Injury. 2020;51(Suppl 3):86-91. https://doi.org/10.1016/j. injury.2019.09.024

29. Pinto D, Manjunatha K, Savur AD, Ahmed NR, Mallya S, Ramya V. Comparative study of the efficacy of gentamicin-coated intramedullary interlocking nail versus regular intramedullary interlocking nail in Gustilo type I and II open tibia fractures. Chin J Traumatol. 2019;22(5):270-3. https:// doi.org/10.1016/j.cjtee.2019.03.006.

30. Moghaddam A, Graeser V, Westhauser F, Dapunt U, Kamradt T, Woerner SM et al. Patients' safety: is there a systemic release of gentamicin by gentamicin-coated tibia nails in clinical use? Ther Clin Risk Manag. 2016:12: 1387-93. https://doi.org/10.2147/TCRM.S107398.

31. Trickett RW, Mudge E, Price P, Pallister I. A qualitative approach to recovery after open tibial fracture: The road to a novel, patient-derived recovery scale. Injury. 2012;43(7):1071-8. https://doi.org/10.1016/j.injury.2 012.01.027.

32. Brinker MR, Hanus BD, Sen M, O'Connor DP. The devastating effects of tibial nonunion on health-related quality of life. J Bone Joint Surg Am. 2013; 95(24):2170-6. https://doi.org/10.2106/JBJS.L.00803.

33. Johnson L, Igoe E, Kleftouris G, Papachristos IV, Papakostidis C, Giannoudis PV. Physical health and psychological outcomes in adult patients with long bone fracture non-unions: evidence today. J Clin Med. 2019:8(11):1998. https://doi.org/10.3390/jcm8111998.

34. Eliezer EN, Haonga BT, Morshed S, Shearer DW. Predictors of reoperation for adult femoral shaft fractures managed operatively in a Sub-Saharan country. J Bone Joint Surg Am. 2017 Mar 1:99(5):388-95. https://doi.org/10.2106/ JBJS.16.00087.

35. Angerpointner K, Ernstberger A, Bosch K, Zeman F, Koller M, Kerschbaum M. Quality of life after multiple trauma: results from a patient cohort treated in 
a certified trauma network. Eur J Trauma Emerg Surg. 2019. https://doi.org/1 0.1007/s00068-019-01160-y.

36. Jansson KÅ, Granath F. Health-related quality of life (EQ-5D) before and after orthopedic surgery. Acta Orthop. 2011:82(1):82-9. https://doi.org/10.3109/1 7453674.2010.548026.

37. Schmitz P, Lüdeck S, Baumann F, Kretschmer R, Nerlich M, Kerschbaum M. Patient-related quality of life after pelvic ring fractures in elderly. Int Orthop. 2019;43(2):261-7. https://doi.org/10.1007/s00264-018-4030-8.

\section{Publisher's Note}

Springer Nature remains neutral with regard to jurisdictional claims in published maps and institutional affiliations.

Ready to submit your research? Choose BMC and benefit from:

- fast, convenient online submission

- thorough peer review by experienced researchers in your field

- rapid publication on acceptance

- support for research data, including large and complex data types

- gold Open Access which fosters wider collaboration and increased citations

- maximum visibility for your research: over $100 \mathrm{M}$ website views per year

At BMC, research is always in progress.

Learn more biomedcentral.com/submissions 